\title{
Use of Umblical Cord Blood in the Management of Leukaemia
}

\author{
Obeagu Emmanuel Ifeanyi ${ }^{1 *}$ and Obeagu Getrude Uzoma ${ }^{2}$ \\ ${ }^{1}$ Medical Laboratory Services, , Michael Okpara University of Agriculture, Nigeria \\ ${ }^{2}$ Department of Nursing Science, Ebonyi State University, Nigeria
}

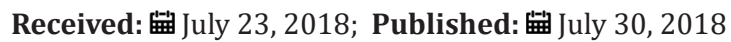

*Corresponding author: Obeagu Emmanuel Ifeanyi, Medical Laboratory Services, University Health Services, Michael Okpara University of Agriculture, Umudike, Abia State, Nigeria

\begin{abstract}
Leukaemia is a blood disorder caused by uncontrolled production and release of abnormal blasts cells in the bone marrow and in the circulation. Treatment of leukaemia has been a great challenge and many patients die. The initial methods of treatments were chemotherapy and radiation which target the leukaemic cells. There is a concern on the management of leukaemia patients. This paper was written to enlighten the public on the need to utilize umbilical cord blood in the management of leukaemia patients.
\end{abstract}

Keywords: Umbilical Cord Blood; Management; Leukaemia

\section{Introduction}

Umbilical cord blood is rich in stem cells for saving life especially in leukaemia cases. It may be advantageous to utilize donor cord blood over self cord blood in treatment of neoplastic cases. Cord blood is collected from umbilical cord and placenta following the delivery of a baby and when it meets the requirements is stored at a cord blood bank for future use [1]. Umbilical cord blood should not be wasted. Transfusion of blood- forming stem cells is done to restore the capacity of the bone marrow to from blood and immune cells. It is reported that donor umbilical cord blood transfusion is progressively utilized care in Pediatric subjects with many disease especially leukaemia [2-4]. Cord blood marrow transplant action and even better than peripheral blood stem cells $[5,6]$.

\section{Use of Umbilical Cord Blood in the Management of Leukaemia}

Many persons waste cord blood of new borns in the hospitals which in not wise at all because it is veritable tool in the management of leukaemia. The major treatments in leukaemia are chemotherapy and radiation. These treatment options target the leukaemic cells but the use of umbilical cord blood through transfusion of the units of cord blood to the patients. Leukaemia is formed by uncontrolled formation and release of blast cells into circulation. These blast cells that dominate the circulation are abnormal proteins that cannot mount any defense against invading pathologenic organism resulting to immunodeficiency exposing the patients to a lot of opportunistic infection and anaemia. In fact a lot of leukaemic patients die as a result of anaemia due to infiltration of bone marrow with abnormal blast cells which disrupt erythropoiesis or causing ineffective erythropoiesis resulting to even dyscrasia of blood [7]. Actually, the main cause of leukaemia may not have been known but some of the risk factors are known as genetic predisposition of the patients such as in Faconic anaemia, exposure to some chemicals such as benzene and heavy metals which lodge in the bone marrow causing dyserythroplastic syndrome and leukaemia. Also, radition and eating life style may contribute to the development of leukaemia. Individuals who eat more of preserved foods may be at high risk of developing leukaemia. Some infections may likely expose persons to leukaemia especially some viral infections acting as oncogenes.

Human umbilical cord blood is a promising tool in the management of leukaemia patients. The transfusion of cord blood enables the patient restore dysfunctional bone marrow by replacing abnormal cells and regenerating viable cells. The umbilical cord blood contain stem cells and progenitor cells the stem cells are pluripotent and totipotent with multiplicity and regeneration ability. Umbilical cord blood can be safely pooled together as a unit of blood to be transfused and properly stored and used when needed. The health workers are directly involved with child 
bearing should take note to prevent wasting umbilical cord blood because it will perform surprising healing on leukaemia patients. It is not only the blast cells formed in the leukaemia patients that will be corrected other cell lines such as the erythrocytes and thrombocytes. The immunological and haematological response of the leukaemia patients improve with the transplantation of cord blood. This natural process of managing leukaemia patients is better that chemotherapy and radiation therapy. This cord transplantation can be received by children and adults and ensures fast and quality recovery for the leukaemia. Researches in cord blood should become highly dynamic be involved in finding a better and a more promising ways to utilize cord blood in the management of leukaemia patients. This will help even the researchers are frequently exposed to heavy metals in the laboratory during their researching process and that is the reason many researchers die as a result of leukaemia. The treatment option will be utilized by the health workers to improve the well-being of the leukaemia patients [8].

\section{Conclusion}

Leukaemia is formed by uncontrolled synthesis and release of blast cells in the bone marrow and circulation. Leukaemia leads to immune suppression and anemia. There is high level of morbidity and mortality rate among the patient. Treatment with cord blood has shown much recovery for even patients who had reduced chances of survival. Cord blood is a great tool in the management of leukaemia patients. This natural process of treating leukaemia patients should be greatly explored and utilized adequately to some lives even those who have lost hope of living by replacing abnormal cells in the bone marrow and in the circulation. Researches should be done in this area to harness the potentials of cord blood in treating leukaemia so that many persons will not be dying every time.

\section{References}

1. (2007) The American Acedemy of Pediatrics. Policy Statement. Pediatrics 119: 165-170.

2. Rocha V, Labopin M, Sanz G, Arcese W, Schwerdtfeger R, et al. (2004) Transplants of umbilical-cord blood or bone marrow from unrelated donors in adults with acute leukemia. N Engl J Med 351(22): 2276-2285.

3. Kurtzberg J, Prasad VK, Carter SL, Wagner JE, Baxter Lowe LA, et al. (2008) Results of Cord Blood Transplantation Study (COBLT): clinical outcomes of unrelated donor umbilical cord blood transplantation in pediatric patients with hematologic malignancies. Blood 112(10): 43184327.

4. Martin PL, Carter SL, Kernan NA, Sahdev I, Wall D, et al. (2006) Results of the cord blood transplantation study (COBLT): outcomes of unrelated donor umbilical cord blood transplantation in pediatric patients with lysosomal and peroxisomal storage diseases. Biol Blood Marrow Transplant 12(2): 184-194.

5. MacMillan ML, Weisdorf DJ, Brunstein CG, Cao Q, DeFor TE (2009) Acute graft-versus-host disease after unrelated donor umbilical cord blood transplantation: analysis of risk factors. Blood 113(11): 2410-2415.

6. Rocha V, Kabbara N, Ionescu I, Ruggeri A, Purtill D, et al. (2009) Pediatric related and unrelated cord blood transplantation for malignant diseases. Bone Marrow Transplant 44(10): 653-659.

7. Barker JN, Martin PL, Coad JE, DeFor T, Trigg ME, et al. (2001) Low incidence of Epstein-Barr virus-associated posttransplantation lymphoproliferative disorders in 272 unrelated- donor umbilical cord blood transplant recipients. Biol Blood Marrow Transplant 7(7): 395399.

8. Gong JZ, Bayerl MG, Sandhaus LM, Sebastian S, Rehder CW, et al. (2006) Posttransplant lymphoproliferative disorder after umbilical cord blood transplantation in children. Am J Surg Pathol 30(3): 328-336.
CC (i) This work is licensed under Creative

To Submit Your Article Click Here: $\quad$ Submit Article

DOI: $10.32474 /$ OAJOM.2018.02.000138

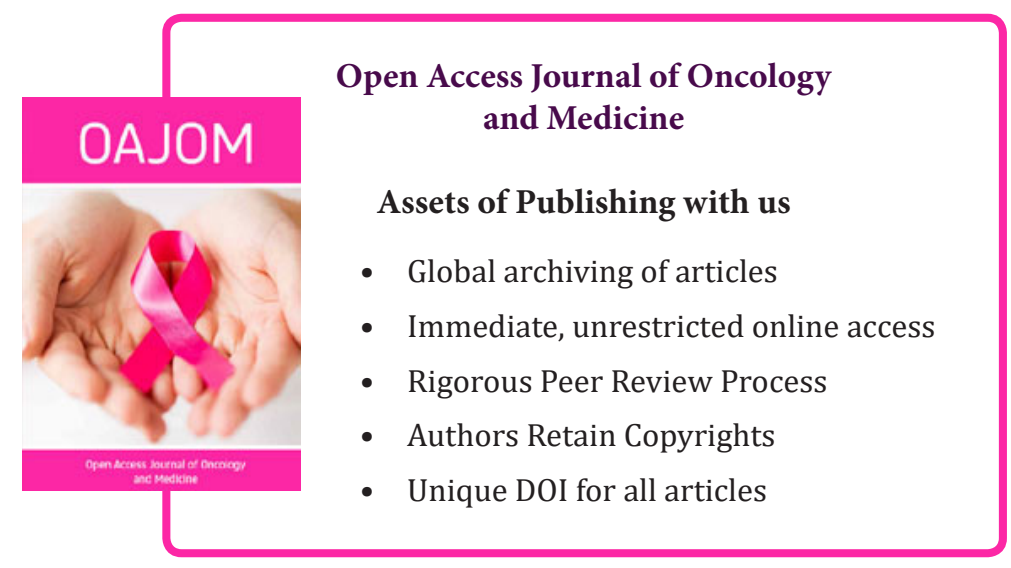

